\title{
Experimental Study of the Impact of the Media Context Appreciation on the Attitude of Children towards the Advertising Message
}

\author{
Fatma Besbes Khouaja ${ }^{1,2,3,4}$ and Néji Bouslama ${ }^{1}$ \\ ${ }^{1}$ FSEG - Tunis - URAM $/{ }^{2}$ IAE $-{ }^{3}$ CAEN $-{ }^{4}$ NIMEC, Tunisia
}

\begin{abstract}
Despite the importance of the research studies conducted in the field of marketing and children, reflection on this young market and more particularly on the effects of the media context on the children's persuasion process is rare. Starting from this observation, the current study is set to investigate the impact of a TV program appreciation by children on their attitudes towards the advertisements surrounding this program (AAD). The experimental study that we have conducted reveals the existence of a positive and significant relation between the program evaluation (i.e. program liking) and AAD. Both the theoretical contributions and the managerial implications of such a result will be discussed in this paper.
\end{abstract}

Keywords: Children attitude, Media context, TV Program liking, Attitude towards the advertisement.

\section{Introduction}

Nowadays, there is full agreement that children have become full consumers. Indeed, they have become more and more influential, as they are not only consumers, but also direct or indirect prescribers of family products. They are equally future consumers of goods and services. As stated by Mc Neal (1992), children make up a triple market: a primary market as they set consumption acts, an important market of prescribers, and finally a future market. As a consumer and a prescriber, the child enjoys a privileged relationship with brands. These are part of his daily life. According to some researchers, "the child refers to brands rather than to products" (Pecheux and Derbais 2002). In this respect, advertising in general, and advertising on television in particular, are for the young consumer, one of the main sources of information on the products and brands of which he is fond of (Guichard 2000). Research investigating the influence of adverting on children has considerably developed in the field of marketing, seeing the heavy weight of the child in the family's shopping decisions, and the privileged nature of his relationship with TV advertising (Bree 1993; Young 1990). Works dealing with the persuasion process of advertising (Derbaix 1982; Pecheux and Derbaix 2002; Phelps and Hoy 1996) are among the most important in the literature. Thus, models have been proposed, which describe the mechanism of the persuasion process in a child (i.e. how his attitude to a brand develops) under the effect of advertising (Derbaix 1982; Derbaix et al. 1997; Pecheux and Derbaix 2002; Phelps and Hoy 1996; Moore Shay and Lutz 2000). All the studies conducted on this young target audience have led to the same conclusion: the attitude towards the advertisement (AAD) contributes incontestably to the formation of the attitude towards the brand (AB). According to these studies, the attitude towards the advertisement would be the most reliable criterion of advertising efficiency to be considered, if the persuasion process among children is to be understood (Derbaix and Bree 1997; Moore-Shay and

Copyright (C) 2011 Fatma Besbes Khouaja and Néji Bouslama. This is an open access article distributed under the Creative Commons Attribution License unported 3.0, which permits unrestricted use, distribution, and reproduction in any medium, provided that original work is properly cited. Contact author: Fatma Besbes Khouaja e-maill: fatbesbes@yahoo.fr 
Lutz 2000). It is the peripheral process of persuasion - through the impact of advertisement appreciation on $\mathrm{AB}$ - which is most often at work with children. This fact is all the more true as beliefs towards a brand seem to play no role in determining the attitude towards the same brand (Derbaix and Bree 1997; Pecheux and Derbaix 2002; Pecheux and Derbais 2003).

Within normal exposure conditions, television advertisements are never broadcast separately, they are rather inserted within a context of television programming, which is itself likely to influence the advertisements. The scientific literature dealing with an adult audience has investigated this issue and concluded that TV programs surrounding advertisements are determining factors in the efficiency of these advertisements (Goldberg and Gorn 1987; Mathur and Chattopadhyay 1991; Murry, Laastivicka and Sing 1992; Soldow and Principe 1981). Indeed, during the last two decades, many studies have investigated insertion contexts, particularly the programs in which advertisements are included. These studies have pondered the impact of several variables related to a program on the efficiency of advertising. Such variables include implication in the program, beliefs towards the program, attention to the program, and they constitute the cognitive dimension of the program as well as the mood induced by the program, the intensity and the quality of the emotions raised by the program, and the appreciation of the program representing its emotional dimension. Besides, these studies have covered cognitive measures of advertising efficiency -such as remembering or recognizing advertisements or brands- as well as emotional measures - such as emotional reactions induced by these advertisementsor the attitude towards these advertisements and the promoted brand. Even though they are characterized by the lack of consensus over a number of themes, these works, which are specific to the media context, agree on the importance of the "program appreciation" variable in determining advertising efficiency in relation to emotional reactions, which have long been considered as the major mediators of effects of the programming context.

Although the child is keeping a privileged relationship with the TV medium, and that he is becoming more and more addicted to it at an ever earlier age, there are no significant research works which actually shed light on the relationship between the child, advertising and the TV programs in which it is inserted. Therefore, the investigation of the effects of TV programming context on the persuasion process within this young market has remained scarce (Pecheux and Derbais 2003 ; Pecheux, Derbaix and Poncin 2006; Prasad and Smith 1994). The few studies carried out have dealt with the emotional dimension of the program. Only one study has explored the role of the appreciation of a program in advertising persuasion, it is the study conducted by Pecheux, Derbaix and Poncin (2006). Despite the fact that the literature on the effect of the media context targeting a young audience is even more scarce, the tendency seems to be similar: the appreciation of a TV program would be a key reaction in the persuasion process. Thus, it would be legitimate to wonder if an advertisement is perceived as being more or less efficient according to whether it is inserted within an environment that is pleasant to the child or not.

Despite its importance which is recognized at the theoretical, as well as, the empirical levels (Coulter 1998; Murry and Dacin 1996; Murry, Laastivicka and Sing 1992), program appreciation has not been the object of numerous studies, neither among adults nor among children (the only study known is that led by Pecheux, Derbais and Poncin 2006). In order to fill the gap and be in keeping with the suggestions of previous works, our research takes into consideration this response to a given TV program. Thus, our objective would be to test the causal impact of the appreciation of a program on the persuasion of children through advertising. A major ambition of the current research is showing the existence of a possible contrast process between the program and the advertisement. 
Digging into this research theme related to the effect of the media context presents several implications, of an academic as well as a managerial order. On the academic level, the present work would allow to define an area of research that has not been well explored in the field of child-oriented marketing. Besides, it widens the knowledge related to the process of attitude formation in this young target. On the managerial level, on the other hand, the implications of such a study would primarily interest the media planners, whom the study will help in their choice when acquiring advertising spaces. It would equally be of interest to advertisers, as it offers a new monitoring criterion that could be used when pretesting an advertisement's efficiency. On the whole, the results of this study would allow a better understanding of the television environment of advertising screens.

Our work is divided into four parts. The first part exposes the conceptual framework and the research hypotheses. The second one is devoted to the research experimentation. The two last parts present and discuss the findings of the research.

\section{Theoretical Development and Research Hypothesis}

\section{Program Liking and AAD}

Analysis of the literature on the media context shows that the programming environment has often been dealt with from its emotional dimension (i.e. the emotions it creates), and only in rare cases has its evaluating dimension (i.e., its appreciation) been considered (Coulter 1998; De Pelsmacker, geuenes and Anckaert 2002; Murry and Dacin 1996; Murry, Laastivicka and Sing 1992; Schumann 1986). One of the objectives of our research is to closely observe this reaction to a program that is its appreciation.

Some researchers have tried to define the concept of appreciation of the programming context. All of them have taken the same perspective, that of evaluation (De Pelsmacker, Geuens and Anckaert 2002; Murry, Lastoviska and Sing 1992; Schumann 1986). The simplest and most general definition is the one proposed by Schumann (1986) who considers the appreciation of a program as being "a conscious and global evaluation of, or an attitude towards, a television program". Similarly, De Pelsmacker, Geuens and Anckaert (2002) define the construct as being "the fact that someone finds a particular context interesting or boring, following which he would read a similar article or watch a similar program" (p51).

Compared to this view, other researchers have added the experiential aspect of TV programs consumption. According to Murry, Lastoviska and Sing (1992), " the appreciation of a program is the result of the evaluation of the experience of being exposed to this program". In a similar way, Coulter (1998) defines the concept as being " a summary evaluation of the experience of viewing a television program». Likewise, Unger and Kernan (1983), state that the appreciation of a program reflects the intrinsic satisfaction raised by the experience of being exposed to this program. The definitions provided by Murry, Lastoviska and Sing (1992), but also by Coulter (1998) and Unger and kernan (1983), do all agree on the experiential perspective, earlier proposed by Holbrook and Hirschman (1982) which states that the consumption activity includes the search for fantasy, feelings and amusement.

When it comes to the relations between "Program appreciation" and "Criteria of advertising efficiency", the research falls short of providing convincing results. The most widespread trend is the one that advocates positive effects, and according to which the more a TV viewer likes a TV program, the stronger his response to the advertisement broadcast before, during or after it. More precisely, the person who likes a given program will be in a positive mood and will be likely to transfer this favorable attitude or good mood to the advertising stimulus following this program (De Pelsmacker et al, 2002). This is all the more true that the attention given to a highly appreciated program will be 
kept active, rather than be dissipated by the launching of an advertising screen (Krugman 1983). As a result, both the evaluation of the advertising stimulus and its memorization will be reinforced. All the theories related to the transfer of emotions, such as the hypothesis on the congruence of moods, the temporary association between the program and the advertisement, the heuristic effect, the halo effect, and the excitement transfer theory are pertinent and can be accounted for in explaining such an effect.

In a synthesis work dealing with the impact of the programming context on advertising persuasion, Schaumann and Thorson (1990) state that it is generally within the framework of impact studies that we can demonstrate that programs having a very high audience rate (i.e., the ones that are the most interesting or pleasant) are the ones holding the highest probability to be subjected to advertising. They quote different samples showing that the programs that are liked most are associated with the advertisements that are best memorized (Barclay et al, 1965; Clancy and Kweskin 1971; Leach 1981; Priemer 1983; Smith 1956; Twyman 1974; for further details refer to the article of Schaumann and Thorson (1990) ). The explanation of these results is that the more favorable the attitude towards a program is, the greater the attention paid to it; the less zapping there is, the higher the memorization and recognition of the promoted products (Twyman 1974).

Several studies have investigated the relation between the TV broadcast surrounding an advertisement and the memorization of the latter. However, very few of these studies were interested in the impact of context on the attitudes of the viewers (AAD and $A B$ ) (Schauman and Thorson 1990). A very old study led by the Home Testing Institute Inc. (1963) and following the analysis of five different studies, came to the conclusion that the higher the appreciation or preference of and the interest in a program, the more probable the change in attitude towards the advertisement inserted in it. Likewise, Television Audience Assessment, Inc. (1984), together with a Boston-based firm have stated -relying on the outcomes of several studies- that the appreciation of a program is positively correlated with the measures of remembrance and the attitudes towards the advertisement and the brand (cited in Schauman and Thorson 1990. p10). Through the exploitation of archival data related to 56 TV programs sponsored by GE during nine years, Krugman (1983) has confirmed the favorable influence of the best-liked programs on advertisements. Thus, attitude scores were higher in the shows which interested the audience than in others. The author commented that, through a halo effect, the advertisements inserted in broadcasts which are judged as "pleasant" or "interesting" benefit from a more favorable judgment.

In experimental situations, the trend seems to be the same: most researchers reached results that are in keeping with the positive effects thesis. These researchers found that the appreciation of a context leads, in a similar way, to a change in attitude towards the advertisements breaking into it. Therefore, viewing an advertisement when the evaluation of the program is salient would influence $A A D$ and $A B$ in congruence with the valency of the program appreciation (Coulter 1998; Murry, Lastoviska and Sing 1992; Pelsmacker, Geuens and Anckaert 2002; Schumann 1986).

Schumann (1986) was among the first to notice that advertisements inserted in programs that are appreciated lead to rather positive impressions on the promoted products, which was not the case when those same advertisements were presented in disliked programs. Later, through an experimentation in which the emotions (positive, negative or neutral) started by a program were manipulated, Murry, Laastivicka and Sing (1992) proved that if a viewer liked a program he would equally like the advertisement broadcast in it. Therefore, there is a positive impact on the attitude towards both the advertisement and the brand. They equally emphasized the mediating role of the attitude towards the advertisement between the program appreciation and the attitude towards the brand. Contrarily to 
previous research (for example Goldberg and Gorn 1987), the study of Murry, Laastivicka and Sing (1992) shows that emotions raised by a program have no influence on the evaluation of the advertisements surrounded by this program. These results have had some implications on the subsequent studies dealing with this field of research. In fact, Coulter (1998) has later confirmed the conclusions of Murry, et al, by reporting a positive correlation between advertisement evaluation and program appreciation. Besides, he noticed that program appreciation was a mediating variable, in the same way as cognitive responses to the program, of the effects of positive and negative emotions raised by the program on the evaluation of the advertisement and the brand. It is essentially the findings of this researcher which have consolidated the role of the program appreciation variable in the advertising persuasion process.

More recently, De Pelsmacker, Geuens and Anckaert (2002) have studied the effect of the appreciation of two types of contexts television and print- on the efficiency of advertisements inserted in them, in terms of AAD and remembrance. Globally, it is the excitement transfer theory, and not the cognitive capacity theory, that best supports the findings of this study, contrarily to the authors' anticipations. They have shown that a liked program leads to more favorable attitudes towards the advertisement. In this way, a positive feeling coming out of being exposed to a highly-appreciated program is transferred (or incorrectly attributed) to the attitude towards the advertisement.

Some research works, even though limited in number, have concluded on negative consequences of the appreciation of a program on the assessment and cognitive responses to an advertisement, thus confirming the negative effects hypothesis. It has been shown that "the interruption of a program by advertisements" irritates viewers, no matter the type of the program viewed. This is all the more true when viewers find the program interesting or are eager to know what follows (Steiner 1963;
Steiner 1966: cited in Schumann and Thorson 1990). Therefore, advertising messages tend to be physically avoided or mentally filtered, which inevitably weakens the memorization of the advertisement and affects the attitude towards it. This observed phenomenon, i.e., the fact that advertisements which are inserted in liked programs suffer a less favorable judgment, reflects a different process from that of emotional transfer. More particularly, this result supports the cognitive capacity theory and the feelings-as-information theory. According to a study conducted by De Pelsmacker, Geuens and Anckaert (2002) and cited above, advertisements broadcast within a printed context that is strongly appreciated are much less memorized (in terms of recalling the brand and the advertisement) than those inserted within a less appreciated context. This means that a liked printed context might lead to diverting from the advertisement (De Pelsmacker, Geuens and Anckaert 2002).

Only one research work has investigated the influence on children of the appreciation of a program surrounding advertisements on the efficiency of these advertisements (Pecheux, Derbaix and Poncin 2006). This experimentation relied on the hypothesis of a negative impact of programs that are liked by children on their reactions to advertising in terms of $\mathrm{AAD}$ and $\mathrm{AB}$. The hypothesis has only been checked for AAD. Pecheux, Derbaix and Poncin (2006) have shown that when an advertisement is inserted in a broadcast that is not enjoyed by children such as the News, it is more efficient (better AAD), than when it is inserted in a program that is appreciated by them, such as the Star Academy show. However, the authors could not conclude about the mechanisms underlying this observed phenomenon. According to the authors, the results reached do not reflect an effect of assimilation of the program over the advertisement. Such an explanation would be valid if the authors found that the advertisements interrupting programs which are liked were better assessed than when viewed by a control group (the case where the advertisements were not 
preceded by a TV program). The authors could not either conclude that the advertisements had an effect of contrast, because for this to happen, the evaluation of these advertisements made following the viewing of a program that is not appreciated had to be better than the evaluation made when the same advertisements were viewed in isolation (within the framework of a control group). Improving the research is necessary, say the authors, in order to understand the processes underlying the program's impact on the advertisement directed to an audience of children. On the whole, the results of this study are in keeping with the trend concluding on the negative effects.

By analogy with the findings of Pecheux, Derbaix and Poncin (2006), and contrarily to the predictions of the theories of mood transfer, we suppose that the appreciation of a program would act unfavorably on the advertisement's performance in terms of AAD. Otherwise, a positive attitude towards the program would lead to a positive attitude towards the advertisement. We have observed the behavior of children while they were enjoying the watching of the movie King Lion and the way they reacted to the interruption of the movie by an advertising screen made up of three advertisements promoting products directed to children. This study showed that the interruption of the program by advertisements irritates the children.

\section{General Research Hypothesis}

The appreciation of the program has a significant and negative influence over the attitude towards the advertisement.

\section{Methodology}

\section{Experimental Design}

In order to test the research hypothesis, we have manipulated the appreciation of the program (a highly-appreciated program vs. a program that is only slightly appreciated). More precisely, the children gathered in groups of 25 children each- are submitted at random to two experimental conditions. Under the first condition, the children are exposed to a well-appreciated program, while under the second one, they are exposed to a program that is only slightly liked.

\section{Stimuli}

\section{Selection of Programs}

Six programs are selected: two cartoons, Sassouki and Sinen; two animated movies, Shrek 3 and Ratatouille; and two documentaries, one on animals -Les Mystères de l'Amazone- the other a historical biography, Kabil and Habil. We suppose that the four first programs would be the most appreciated by the children, while the two last the least appreciated. These six programs are broadcast to two groups of children. The first, composed of 50 children aged 10 to 12 , watched three programs. The second group, composed of 40 children of the same age as the members of the first group viewed three other programs. This work is undertaken in a school in the following sequence:

- We inform the children that they will view several programs and that they will have to tell us whether they like what they watched or not.

- Each program is broadcast during 30 minutes.

After each exposition, we hand them out a questionnaire that will measure their reaction to the program, using the scale of Murry et al. (1992).

- We ask them afterwards to classify the 3 programs they watched in a scale of preference.

- Ultimately the children are thanked for their participation.

The pretest results show that the most liked program is the animated movie, Shrek 3 , while the documentary on animals, Les Mystères de l'Amazone, is the least appreciated. As a consequence, these two categories of programs will be selected for the final experimentation. This practice is 
commonly used by researchers (Goldberg and Gom 87). It consists in using different types of programs (comedies, drama, action films) to create different types and levels of reactions to them (positive emotions, negative emotions, intense emotions, favorable attitude to the program, etc.) The benefits of this method are essentially related to the external validity of the results.

\section{Selection of Advertising}

This work is conducted with the same children who attended the broadcasting of the programs. Precisely, the children are presented with a list of brands right after they evaluate the programs they watched, and they are asked to tick those they know. Thereafter, they are invited to mention three types of products which interest them most. Ultimately, we choose an unknown brand (HICI) belonging to a category of products that widely target children, i.e. juices. Working with a brand and an advertisement that are unknown allows us to control a whole series of variables while avoiding an effect of a priori attitude towards the brand, for instance, and/or a heterogeneity in our sample concerning prior expositions to the advertisement. We make sure, relying on another test group, that the advertisement promoting the selected brand is unknown to the children.

The advertising screen is composed of 4 advertisements. The testing advertisement is placed first on the screen. Once the experimental material is selected, we moved on to the pretest procedure as a whole. We precisely want to control the duration of the experimentation. We can equally test our experimental material again. After this pretest conducted among children aged ten we can start the final experimentation.

\section{Participants and Experimental Procedure}

Eight classes from four schools located in four provinces (Tunis, Ariana, Manouba and ben Arous) took part in our experimentation. We exclusively worked with fifth and sixth formers (aged 10 to
12), who are the oldest in those schools. After eliminating the questionnaires that are not filled correctly, we end up with a sample of 291 children.

We first state the disguised objective of the study. In fact, the children will be informed that they will view a TV program, and be asked a set of questions about it afterwards. The advertisements will not be mentioned. Then, we broadcast a twentyminute long audio-visual editing, which starts with the program and ends with the advertising screen. After exactly 15 minutes of exposition to the program, we measure its appreciation (this task is conducted while the broadcast is on). Just when the advertising screen is on and when the first advertisement is over, the video is turned off and we hand out the question related to the first advertisement, that is, the attitude towards the advertisement (AAD). The video is restarted and at the end of the advertising screen, we distribute the questionnaire dealing with the identifying information.

\section{Measures}

The questionnaire involved in our research contains 2 measures. The first is related to the program. The other deals with the advertisement.

\section{Independent variable}

As indicated above, in our literature review, different variables have been used to tackle the effects of the program on adults: the appreciation of the program is the one that we find most pertinent for a children population. There is no measuring scale of a program appreciation that is specially devised for children aged 8 to 12 .

The only scale available and which has been used by authors who worked about children (Pecheux et al. 2006) is the following: I liked the program; I like to watch it again; This program is boring. LISREL was used to validate the measuring model. All the parameters of the Confirmatory Factor Analysis are satisfying: the $(\lambda \mathrm{i})$ are all superior to the 0.5 threshold. This proves a high-quality representation of the items (Table 1). 
Table 1: Confirmatory Factor Analysis of Program Liking Measure

\begin{tabular}{|l|c|}
\hline \multicolumn{1}{|c|}{ Item } & Loading \\
\hline I liked the program & 0.794 \\
\hline I feel like viewing it again & 0.818 \\
\hline This program is boring & 0.756 \\
\hline
\end{tabular}

\section{Dependant Variable}

An efficiency indicator was chosen among the ones classically used with adults (MacKenzie and Lutz 1989; Muehling and Laczniak 1992), and with children (Derbaix and Brée 1997; Moore-Shay and Lutz 2000 ; Phelps and Hoy 1996): the attitude towards the advertisement (AAD). By the way, this option is coherent with the studies conducted about the effects of context on populations of adults and children and in which such effects are often investigated for their impact on the evaluation of the advertisement. The attitude towards the advertisement may be defined as "the evaluating judgment of an advertisement, during or immediately after the exposition to this advertisement» (Derbaix 1995). This construct wasmeasured in the current research, through a one-dimensional six-item scale, initially developed by Derbaix, Blondeau and Pecheux (1999) and which we specifically adapted to Tunisian children aged 8 to 12 . After analyzing the parameters of the Confirmatory Factor Analysis, we kept the 5 following items:

I love this advertisement; I find this advertisement good; I find this advertisement beautiful; I find this advertisement stupid; I feel like viewing this advertisement again. As indicated in Table 2 the $(\lambda \mathrm{i})$ are all superior to the 0.5 and the model provide an acceptable fit to the data.

The scale was provided and accompanied with a reply format comprising 4 points: Disagree totally -Disagree slightly -Agree slightly-Agree totally.

Table 2: Confirmatory Factor Analysis of AAD Measure

\begin{tabular}{|c|c|c|c|}
\hline Item & Loading & Adjustment coefficient & Value \\
\cline { 3 - 4 } & & Chix-deux/ddl & 2.291 \\
\hline I love this advertisement & 0.792 & GFI & 0.990 \\
\hline $\begin{array}{c}\text { I find this advertisement } \\
\text { good }\end{array}$ & 0.860 & AGFI & 0.961 \\
\hline $\begin{array}{c}\text { I find this advertisement } \\
\text { beautiful }\end{array}$ & 0.837 & RMR & 0.018 \\
\hline $\begin{array}{c}\text { I find this advertisement } \\
\text { stupid }\end{array}$ & 0.799 & RMSEA & 0.061 \\
\hline $\begin{array}{c}\text { I feel like viewing this } \\
\text { advertisement again }\end{array}$ & 0.643 & NFI & 0.991 \\
\cline { 2 - 4 } & & CFI & 0.995 \\
\cline { 2 - 4 } & & TLI & 0.988 \\
\hline
\end{tabular}

\section{Results and Discussion}

\section{Manipulation Checks}

A variance analysis between the type of the program (animal vs. animated) and the program appreciation variable was conducted, to check the success of the manipulation of the program appreciation.
Our experiment was a success. In fact, the appreciation scores of the movie Shrek 3 are significantly higher than those of the documentary about animals.

\section{Hypotheses Testing}

We wanted to show that there is a negative and significant correlation between the 
child's attitude towards the program (i.e., the program's appreciation) and his attitude towards the advertisement that interrupts this program. In fact, we thought that interrupting a program by advertising irritates young TV viewers. The results of the test of structural model are globally acceptable. We can notice that the adjustment signs - the normed Chi-deux, the RMSEA, the CFI and the TLI- are good, while the GFI, AGFI, RMR and NFI are getting nearer to the commonly allowed norms. The link between the program appreciation and the attitude towards the advertisement is positive and significant (CR>1.96, $\mathrm{p}<0.01 ; \mathrm{t}=4.791$ ) (see Table 3). The positive sign we got is opposed to our anticipations and to the formulated hypothesis, which leads us to reject it.

Table 3: Confirmatory Factor Analysis of the Structural Model

\begin{tabular}{|c|c|c|c|c|}
\hline \multicolumn{2}{|c|}{ Tested relation } & Standardized coefficient & CR & P \\
\hline AAD & $<-$ & 0.407 & 4.791 & $* * *$ \\
Liking & Value \\
\hline Adjustment coefficient & 2.222 \\
\hline Chix-deux/ddl & 0.865 \\
\hline GFI & 0.836 \\
\hline AGFI & 0.083 \\
\hline RMR & 0.059 \\
\hline RMSEA & 0.893 \\
\hline NFI & 0.938 \\
\hline CFI & 0.930 \\
\hline TLI & \\
\hline
\end{tabular}

The program appreciation has been described, in this work, as a reaction to the program that had very little consideration on the part of the researchers. Besides, studying it among a children audience is relatively recent (Pecheux et al. 2006). It is actually an evaluation of the pleasure derived from the experience of viewing the program. The results displayed in the table above show that the appreciation of the media context has a positive influence on the child's attitude towards the advertisement surrounding the program. Therefore, the thesis stating a negative and significant impact of the appreciation of a program on the evaluation of the advertising surrounding this program is not supported by our study. Otherwise, and according to our research, the child tends to evaluate an advertisement more favorably if it is broadcast around a TV program that he likes. This outcome is in keeping with the results reached by the majority of the previous research works conducted among adults, but opposite to those found by research on children.
The result reached through the test can be accounted for. In fact, as in the theories of the consumer's socialization and cognitive development, children aged 8 to 12 , i.e. belonging to the concrete operational level, are considered emotional beings who rely on their emotions to evaluate the environment around them. In our case, the child uses his emotional state that is induced by the TV program to evaluate the advertisement representing its environment. Moreover, this result gains its legitimacy from the theories of transfer, specific to the media context, which support a contamination effect towards the advertisement caused by the feelings raised by the program preceding or surrounding it. Thus, this work which is dealing with Tunisian children supports the conclusions of Prasad and Smith (1994) about American children and those of Pecheux and Derbaix (2003) about European children. These conclusions state that it is the assimilation process that is best adapted concerning the transfer of emotional reactions raised by the program 
on the children's responses to advertisements interrupting this program. This result invites marketing experts to consider this response to the program seriously, in order to better control the young viewers' attitudinal response to advertising.

\section{Research Conclusion}

The present article was set to test the effect of the media context appreciation on the advertising performance among a population of children. For this purpose, we have first analyzed the main theoretical and empirical works conducted on this theme, in relation with this fundamental dimension related to the media context. At the conclusion of this survey, two results came out. On the one hand, it has been noticed that, at the current state of knowledge, there is a lack of consensus about a number of themes. Indeed, several theories having opposite implications have been developed in order to account for and predict the effects of the advertising context on the advertising broadcasting. As a corollary consequence, lack of coherent results has characterized this field of research. On the other hand, it has been noticed that the theme of the media context effect on young audiences has not been investigated sufficiently. Then, an experimentation involving 291 schoolchildren aged 10 to 12 was conducted. Globally, it is the trend of positive effects which reflects the process along which the appreciation of a program affects the children's reactions to advertisements. Otherwise, it is the emotion transfer thesis which best accounts for the way a population of children reacts to a program. We should, however, precise that this conclusion is opposed to our predictions.

\section{Theoretical Implication}

The current research has validated the positive impact of the media context appreciation on the children's attitude towards advertisements that are inserted in this media context. Thus, it is an effect of assimilation rather than an effect of contrast that is stressed. This outcome allows us to have a deeper understanding of the underlying mechanisms of the effects of programs on children. Besides, it allows us to put a new AAD determinant forward, AAD being invaluable indicators of the advertising efficiency among a young target.

\section{Managerial Implication}

Apart from the theoretical benefits, we stress the importance of this research for advertisers and media planners. The results we reached would further support the fully justified present practices in the field of advertising insertion in Tunisia. It comes out of the discussions held with some media planners that the best setting for a child-oriented advertisement is around or within programs enjoying high young audience rates that are programs that are well appreciated by children. As confirmed by our study, such practices, translated through increasing investments, lead to a better advertising performance (i.e. higher attitude scores towards the advertisement). This article brought a response to a part of the managers' preoccupations concerning the way an appreciated programming context influences the efficiency of an advertisement that it surrounds.

\section{Relevance for Public Services}

At the end, we emphasize the benefits of our study to the public services. Our findings would make it possible to provide clues to the very old issue, which still prevails in certain countries, of proving the well-founding of the attempts to ban children-oriented advertisements around and within programs destined to children. It should be admitted that our findings prove that such a regulation is apparently justifiable. However, we think that it is too early to draw a final conclusion about the efficiency of advertisements addressed to children in correlation with the program. Future research works will certainly be welcome to bring this matter to a firm conclusion. 


\section{Limitations and Suggestions for Further Research}

This conceptualization is not devoid of limitations. It is right to ask questions about on the one hand the choice of program-related variables and on the other on advertisement-related ones. These variables are probably not the only ones available to tackle the issue of the media context effects on children, this issue being more intricate. Following what has already been done for adult populations, future research could bend on the study of the impact on advertising efficiency of several other variables related to the program, such as the mood created by the program, implication in the program (Kennedy, 1971; Soldow and Principe 1981; Tavassoli, Schultz and Fitzsimons 1995), beliefs towards the program (Aylesworth and Mackenzie 1998; Coulter 1998), and the attention to the program (Nahon and Tassi 1998). These studies could widen the measures of advertising efficiency to cognitive measures (cognitive responses to the advertisement, remembering or recognition of brands advertisements), and to purchase intention.

To sum up, we can say that despite a considerable breakthrough in the understanding of the media context effects on adults, our perception of how young TV viewers are affected by the TV program in their reaction to an inserted advertisement remains limited. Any new reflection on the theme dealing with this young target would certainly contribute to the development of this field of research and have considerable theoretical and practical implications, as it has been mentioned in this article.

\section{References}

Brée, J. (1993). 'Les Enfants, la Consommation et le Marketing,' Ed .Presse universitaire de France.

Coulter K, S. (1998). "The Effects of Affective Responses to Media Context on Advertising Evaluations," Journal of Advertising, vol 2, $\mathrm{n}^{\circ} 4,41-51$.
De Pelsmacker P, Geuenes, M. \& Anckaert. P. (2002). "Media Context and Advertising Effectiveness: The Role of Context Appreciation and Context /Ad Similarity", Journal of Advertising, 31, 2, 49-61.

Derbaix, C. (1982). "L'Enfant, la Communication Publicitaire et la Hiérarchie des Effets," Revue Française du Marketing, Cahier 89, 31-57.

Derbaix, C., Blondeau, S. \& Pecheux, C. (1999). 'L'Enfant et l'Attitude Envers l'Annonce Publicitaire: Mise en Oeuvre du Construit et Précisions Conceptuelles," Recherches et Applications en Marketing, Vol.14, n³, 23-39.

Derbaix, C. M. (1995). "The Impact of Affective Reactions on Attitudes Toward the Advertisement and the Brand : A Step Toward Ecological Validity," Journal of Marketing Research, vol 32, 470-479.

Derbaix, C. M. \& Brée, J. (1997). "The Impact of Children's Affective Reactions Elicited by Commercials on their Attitude Toward the Advertisement and their Attitude Toward the Brand," International Journal of Research in Marketing, 14, 3, 207 229.

Goldberg, M. E. \& Gorn, G. J. (1987). “Happy and Sad TV Programs: How They Affect Reactions to Commercials," Journal of Consumer Research, vol 14 (December). 387-403.

Greer, D., Potts, R., Wright, J. C. \& Huston, A. C. (1982). "The Effects of Television Commercials form and Commercial Placement on Children's Social Behavior and Attention," Child development, 53, (juin). 611-619.

Guichard, N. (2000). 'Publicité Télévisée et Comportement de l'Enfant,' Ed. Economica.

Krugman, H. E. (1983). “Television Program Interest and Commercial Interruption: Are Commercials on Interesting Programs Less Effective?," Journal of Advertising Research, 23, 21-23. 
Mackenzie, S. B. \& Lutz, R. J. (1989). "An Empirical Examination of the Structural Antecedents of Attitude Toward the Ad in an Advertising Pretesting Context," Journal of Marketing, vol 53, 48-65.

Mathur, M. \& Chattopadhyay, A. (1991). "The Impact of Moods Generated by Television Programs on Responses to Advertising," Psychology and Marketing, vol 8 (1). 59-77.

Moore- Shay, E. S. (2000). "Children Advertising and Experiences : A MultiMethod Inquiry," Journal of Consumer Research, 27, 1, 31-48.

Murry, J. P. \& Dacin, P. A. (1996). "Cognitive Moderators of Negative Emotion Effects: Implication for Understanding Media Context," Journal of Consumer Research, 22 (Mars). 439-447.

Murry, J. P., Laastivicka, J. L. \& Sing, S. N. (1992). "Feeling and Liking Responses to Television Programs: An Examination of Two Explanations for Media- Context Effect," Journal of Consumer Research, 18, 441-451.

Pecheux, C. \& Derbaix, C. (2002). “L'Attitude de l'Enfant Envers une Nouvelle Marque : De la Nécessité à une Phase de Fixation ?," Recherche et applications en Marketing, vol 17, n³, 63-79.

Pecheux, C. \& Derbaix, C. (2003). "Le Contrôle de la Publicité Destinée aux Enfants: une Démarche Expérimentale pour étudier les Effets de Contexte," Acte du congrès international de l'AFM 2003, 138-149.

Pecheux, C., Derbaix, C. \& Poncin, I. (2005). "The Control of Commercials Targeting Children: An Experimental Approach to Investigate Context Effects," European Advances in Consumer Research, 7, 1-9.

Phelps, J. E. \& Hoy, M. G. (1996). "The AaDAb- PI Relationship in Children: The Impact of Brand Familiarity and Measurement Timing," Psychology and Marketing, 13,1, 77-105.
Prasad, V. K. \& Smith, L. J. (1994). "Television Commercials in Violent Programming: Experimental Evaluation of their Effects on Children," Journal of the Academy of Marketing Sciences, vol 22, 4, 340-351.

Schumann, D. W. (1986). 'Program Impact on Attitude toward TV Commercials,' Proceedings of Division of Consumer Psychology, ed. J.G. Saegert, DC: American Psychological Association.

Schumann, D. W. \& Thorson, E. (1990). 'The Influence of Viewing Context on Commercial Effectiveness: A SelectionProcessing Model,' Current Issues and Research in Advertising, 12, 1, 1-24.

Soldw, G. F. \& Principe, V. (1981). "Response to commercials as a Function of Program Context," Journal of Advertising Research, vol 21, 59-65.

Steiner, G. (1963). 'The People Look at Television,' New York, Knopf.

Young, B. M. (1990). Television Advertising and Children, Ed. Clarendon Press Oxford. 